\title{
Optimal 1,5-anhydroglucitol cut-off points for diagnosing diabetes based on prevalence of retinopathy in Chinese population
}

\section{Cheng CHEN}

Southeast University Zhongda Hospital

\section{Shanhu QIU}

Southeast University Zhongda Hospital

\section{Ziwei DU}

Southeast University Zhongda Hospital

\section{Haijian GUO}

Jiangsu Provincial Center for Disease Control and Prevention

\section{Bei WANG}

Southeast University

\section{Zilin SUN}

Southeast University Zhongda Hospital

Yao Wang ( $\nabla$ wang_yao100@163.com )

Southeast University Zhongda Hospital https://orcid.org/0000-0001-5433-7360

\section{Research Article}

Keywords: 1,5-anhydroglucitol, diabetes mellitus, diabetic retinopathy, cut-off point

Posted Date: March 7th, 2022

DOI: https://doi.org/10.21203/rs.3.rs-1406302/v1

License: (9) (i) This work is licensed under a Creative Commons Attribution 4.0 International License. Read Full License 


\section{Abstract}

Background: A new glycemic index, 1,5-anhydroglucitol (1,5-AG), can reflect glucose fluctuation over 3-7 days. The aim of this study was to evaluate the possibility of 1,5-AG in diagnosing diabetes based on the prevalence of diabetic retinopathy in the Chinese population.

Method: The study enrolled 3579 adults aged $20-70$ years. Values for 1,5-AG, fasting plasma glucose (FPG), 2-hour postprandial glucose (2hPG), and glycated haemoglobin $(\mathrm{HbA} 1 \mathrm{c})$ were measured. Retinal photographs were taken, and diabetic retinopathy was assessed and graded according to the Early Treatment Diabetic Retinopathy Study (ETDRS). Retinopathy with an ETDRS level $\geq 21$ was defined as diabetic retinopathy, with level $\geq 31$ as "diabetic-specific retinopathy." A receiver operating characteristic curve was used to determine the optimal cut-off point.

Results: Serum 1,5-AG was negatively correlated with FPG, 2hPG, and HbA1c. The 1,5-AG level was significantly lower in the diabetic retinopathy group. The optimal cut-off point of 1,5-AG was $13.05 \mu \mathrm{g} / \mathrm{m}$. At this point, the sensitivity and specificity were $74.1 \%$ and $91.2 \%$, respectively, and the area under the receiver operating characteristic curve was 0.846 . The optimal cut-off point remained unchanged after excluding participants on hypoglycemic medication. Combining 1,5-AG with FPG or HbA1c could raise the specificity in diagnosis.

Conclusion: Our data found that $1,5-\mathrm{AG}$ at $13.05 \mu \mathrm{g} / \mathrm{mL}$ had a good specificity for diagnosing diabetes in the Chinese population. In combination with FPG or HbA1c, 1,5-AG was a good tool for detecting diabetes without symptoms.

\section{Introduciton}

There is a large instance of undiagnosed diabetes in China. The early diagnosis and treatment of diabetes is of vital importance in the prevention of high medical expenditure due to diabetic complications.

A relatively new glycemic index, 1,5-anhydroglucitol (1,5-AG), can reflect glucose fluctuation over 3-7 days. The level of 1,5-AG is usually stable in serum. When glucose levels exceed the renal threshold, 1,5AG reabsorption is reduced by glucose competition, causing a sharp decrease in serum 1,5-AG levels [13]. Several studies [4-7] have reported the feasibility of 1,5-AG for diagnosing diabetes. However, the cutoff point has not yet been established in China.

Diabetic retinopathy (DR) is one of the most specific diabetic microangiopathies [8] and often appears in the early stage. It is often considered as the basis for diagnostic criteria of diabetes mellitus $[9,10]$. The cut-off points to define diabetes that are currently used in clinical practice nowadays (fasting plasma glucose $\geq 7.0 \mathrm{mmol} / \mathrm{L}, \mathrm{HbA} 1 \mathrm{c} \geq 6.5 \%$ ) were established based on the association between glycemic levels and the sharp increase in DR prevalence [11-12]. 
We aimed to explore the optimal diagnostic threshold of 1,5-AG for diabetes in the Chinese population based on the prevalence of DR.

\section{Materials And Methods \\ 2.1 Study population}

We analyzed data from the study "Early identification, early diagnosis and cut-off points of diabetes" conducted by Southeast University. It was a large-scale multi-center study including ten provinces from five districts of China. Ten villages were selected randomly from each province. All household residents aged from 20 to 70 years who volunteered to participate were enrolled in the research. The research began in 2017, and a second follow-up was conducted in 2020. All the participants from Jiangsu and Xinjiang Province during the second follow-up were enrolled in our study. Exclusion criteria were cancer, chronic liver disease, chronic kidney disease, history of glucocorticoid treatment, and participants with incomplete data. In total, 3579 participants were enrolled, consisting of 1370 males and 2209 females. The study protocol was approved by the ethics committee of South-East University. Written informed consent was obtained from all subjects.

\subsection{Physical and biochemical variables}

Physical parameters were collected, including heart rate, blood pressure, height, and weight. Body mass index (BMI) was calculated as weight $(\mathrm{kg})$ divided by the square of height $(\mathrm{m})$. Blood samples were collected after eight hours of fasting. Postprandial blood glucose was collected two hours after the standard $75 \mathrm{~g}$ oral glucose tolerance test (OGTT). High density lipoprotein cholesterol (HDL), low density lipoprotein cholesterol (LDL), total cholesterol (TC), triglycerides, alanine aminotransferase, aspartate aminotransferase, creatinine, uric acid, and $\mathrm{HbA} 1 \mathrm{c}$ were measured. Details were elaborated in our previous study [13]. Levels of 1,5-AG were measured by the GlycoMark assay [14] (Kyowa Medex Co Ltd, Shanghai) in an AU5821 auto biochemistry analyzer (Beckman Coulter, USA), with inter- and intra-assay coefficients of variation of $<2.60 \%$ and $<3.10 \%$, respectively. The estimated glomerular filtration rate was calculated by the Cockgroft-Gault formula.

Bilateral retinal photographs were obtained with a nonmydriatic digital retinal camera (Canon CR-2AF). Two $45^{\circ}$ images were taken of each eye centered on the macula and the optic disk. Topivacaine and phenylephrine were used for pupil dilation when necessary. All the photographs were assessed blindly and separately by two qualified ophthalmologists from the Department of Ophthalmology in Beijing Tongren Hospital.

A questionnaire was collected from each participant concerning age, smoking habit, history of chronic disease (including diabetes), and concomitant use of medication.

\subsection{Definition of diabetes}


(1) Meeting the diagnostic criteria as fast plasma glucose (FPG) $\geq 7.0 \mathrm{mmol} / \mathrm{L}$ and/or 2-hour postprandial plasma glucose $(2 \mathrm{hPG}) \geq 11.1 \mathrm{mmol} / \mathrm{L}$ according to WHO guidelines [15]; (2) self-reported diabetes; (3) previous or present antidiabetic medication. Participants who met any one of the criteria (1) - (3) were defined as having diabetes, and those who only met criterion (1) were defined as newly diagnosed with diabetes.

\subsection{Definition and classification of diabetic retinopathy}

DR was assessed based on the Early Treatment Diabetic Retinopathy Study adaptation of the modified Airlie House classification of DR, which was elaborated in the Wisconsin Epidemiologic Study [16, 17]. DR score was assessed based on the worse eye. According to the Wisconsin study, participants with an ETDRS score $\geq 21$ were defined as having DR. Among them, EDTRS = 21 was defined as very mild nonproliferative diabetic retinopathy (NPDR); EDTRS = 31 as mild NPDR; EDTRS = 43 as moderate NPDR [18, 19]. In this study, we defined retinopathy with an EDTRS level $\geq 31$ as "diabetic-specific retinopathy," indicating the existence of diabetes.

\subsection{Statistical analysis}

Normality was tested using the Kolmogorov-Smirnov test. All variables were expressed as median (interquartile range). T-test or ANOVA was used to compare differences between groups. Pearson's correlation was used to examine the relationships between 1,5-AG and FPG, $2 \mathrm{hPG}$, and $\mathrm{HbA} 1 \mathrm{c}$.

We drew a line chart to evaluate the relationship between the prevalence of different levels of DR and 1,5AG deciles and estimate the best cut-off point from the curve trend.

Receiver operating characteristic (ROC) curves were plotted to assess the ability of 1,5-AG in detecting any DR or diabetic-specific retinopathy. The Youden index was calculated as the sum of sensitivity and specificity minus one, and was used to identify the optimal cut-off threshold to discriminate any DR or diabetic-specific retinopathy.

Multivariate logistic regression was constructed to further examine the association between 1,5-AG and the prevalence of DR. Age, gender, BMI, hypertension, triglyceride, TC, HDL, and LDL were adjusted.

We then drew an ROC curve in the population, excluding individuals with hypoglycemic therapy. We examined the diagnostic efficiency of 1,5-AG, FPG, and HbA1c in this population and also evaluated the ability of 1,5-AG to diagnose diabetes in combination with FPG or HbA1c.

SPSS software (version 20, SPSS Inc., Chicago, IL, USA) and MedCalc19.4 were used for the statistical analyses. $\mathrm{P}<0.05$ was considered statistically significant.

\section{Results}

\subsection{Baseline characteristics}


Among the 3579 participants, 845 (23.61\%) had diabetes, and 163 (4.55\%) were newly diagnosed diabetes. 196 participants had EDTRS $\geq 21$, and the prevalence of DR was $5.48 \%$ among the entire population and $10.4 \%$ among people with diabetes.

As shown in Table 1, levels of FPG, $2 \mathrm{hPG}$, and HbA1c were higher in the DR group than in the non-DR group, and much higher among people with ETDRS $\geq 31$. On the contrary, 1,5-AG decreased among the more severe DR group. The DR group had higher systolic blood pressure and HDL and a higher prevalence of diabetes. 
Table 1

Characteristics of study population by diabetic retinopathy status

\begin{tabular}{|c|c|c|c|c|}
\hline & Non-DR & any $D R$ & $\begin{array}{l}\text { diabetic-specific } \\
\text { retinopathy }\end{array}$ & p \\
\hline $\mathrm{N}$ & 3383 & 196 & 54 & \\
\hline Age & $55.9(50.65,62.55)$ & $56.1(50.95,63.2)$ & $56.9(51.17,66)$ & 0.021 \\
\hline Gender (male\%) & $38.08 \%$ & $41.49 \%$ & $45.10 \%$ & 0.189 \\
\hline Diabetes(\%) & $22.82 \%$ & $44.68 \%$ & $78.43 \%$ & $\begin{array}{l}< \\
0.001\end{array}$ \\
\hline $\mathrm{FPG}(\mathrm{mmol} / \mathrm{L})$ & $5.36(5.04,5.85)$ & $5.74(5.16,8.08)$ & $8.41(4.78,10.76)$ & $\begin{array}{l}< \\
0.001\end{array}$ \\
\hline 2hPG(mmol/L) & $6.94(5.93,8.35)$ & $7.82(6.55,9.23)$ & $8.65(7.32,10.89)$ & 0.027 \\
\hline HbA1c(\%) & $5.6(5.3,6.0)$ & $5.85(5.55,7.28)$ & $8.1(6.4,9.3)$ & $\begin{array}{l}< \\
0.001\end{array}$ \\
\hline $\begin{array}{l}\text { Serum1,5- } \\
\text { AG }(\mu \mathrm{g} / \mathrm{mL})\end{array}$ & $28.6(21.6,35.6)$ & $21.15(8.3,30.53)$ & $5.3(2.0,17.1)$ & $\begin{array}{l}< \\
0.001\end{array}$ \\
\hline Serum UA $(\mu \mathrm{mol} / \mathrm{L})$ & $294(246,354)$ & $289(230,352)$ & $290(214,344)$ & 0.120 \\
\hline $\mathrm{TC}(\mathrm{mmol} / \mathrm{L})$ & $4.54(3.99,5.15)$ & $4.50(4,5.11)$ & $4.40(4.01,5.14)$ & 0.482 \\
\hline Triglyceride(mmol/L) & $1.34(0.97,1.93)$ & $1.50(1.03,1.98)$ & $1.50(1.08,1.68)$ & 0.005 \\
\hline $\mathrm{HDL}(\mathrm{mmol} / \mathrm{L})$ & $1.42(1.26,1.60)$ & $1.37(1.22,1.54)$ & $1.37(1.23,150)$ & 0.022 \\
\hline LDL(mmol/L) & $2.49(2.08,2.96)$ & $2.54(2.10,2.93)$ & $2.49(2.13,2.93)$ & 0.636 \\
\hline $\begin{array}{l}\text { eGFR } \\
(\mathrm{mL} / \mathrm{min} \times 1.73 \mathrm{~m} 2)\end{array}$ & $\begin{array}{l}\text { 134.73(115.49, } \\
155.41)\end{array}$ & $\begin{array}{l}\text { 138.65(115.32, } \\
158.49)\end{array}$ & $\begin{array}{l}\text { 127.82(105.92, } \\
171.65)\end{array}$ & 0.754 \\
\hline $\mathrm{SBP}(\mathrm{mmHg})$ & $134(121,147)$ & $142(127,155)$ & 151(138, 167) & $\begin{array}{l}< \\
0.001\end{array}$ \\
\hline DBP(mmHg) & $84(76,92)$ & $86(78,94)$ & $87(81,97)$ & 0.081 \\
\hline $\operatorname{BMI}\left(\mathrm{kg} / \mathrm{m}^{2}\right)$ & $\begin{array}{l}\text { 24.91(22.72, } \\
27.22)\end{array}$ & $25.35(23.17,27.46)$ & $25.39(22.58,27.41)$ & 0.369 \\
\hline \multicolumn{5}{|c|}{ Data are given as percentage or Median (interquartile range). } \\
\hline \multicolumn{5}{|c|}{$\begin{array}{l}\text { SBP, systolic blood pressure; DBP, diastolic blood pressure; FPG, fasting plasma glucose; } 2 \mathrm{hPG}, 2 \\
\text { hours postprandial plasma glucose; UA, uric acid; TC, total cholesterol; HDL, high density lipoprotein; } \\
\text { LDL, low density lipoprotein; 1,5-AG, 1,5-anhydroglucitol; BMI, body mass index; eGFR, estimated } \\
\text { glomerular filtration rate. }\end{array}$} \\
\hline
\end{tabular}

There were significant negative relationships between 1,5-AG FPG, $2 \mathrm{hPG}$, and $\mathrm{HbA} 1 \mathrm{c}$, especially in the DR group. In the group with an ETDRS level $\geq 31$, the correlation index with FPG, 2hPG, and HbA1c were - 


\subsection{Cut-off points of 1,5-AG for diagnosing diabetes}

Figure 1 shows the prevalence of different levels of DR by 1,5-AG deciles. The prevalence of three different levels of DR all decreased sharply between the first and second deciles, corresponding to a 1,5AG level $\leq 13.2 \mu \mathrm{g} / \mathrm{mL}$. The prevalence of any DR (ETDRS $\geq 21$ ) was $18.99 \%$ in the first decile and $4.74 \%$ in the second decile. The prevalence of diabetic-specific retinopathy (ETDRS $\geq 31$ ) was $11.17 \%$ and $0.56 \%$ in the first and second decile, respectively.

Figure 2 shows the ROC curve of 1,5-AG for discriminating DR (any DR or diabetic-specific retinopathy). The area under the curve for detecting diabetic-specific retinopathy was $0.846(0.775-0.917)$ and for detecting any DR was only $0.66(0.61-0.71)$.

We analyzed the cut-off points based on the ROC curve of diabetic-specific retinopathy (Fig. 2b). At the 1,5-AG cut-off point of $13.05 \mu \mathrm{g} / \mathrm{mL}$, we got the greatest Youden index. The sensitivity and specificity were $74.1 \%$ and $91.2 \%$, respectively. We also analyzed some other points with a relatively high Youden index. As can be seen in Table 2, the sensitivity for diagnosing diabetes increased slightly as the level of 1,5-AG increased, accompanied by sharp decreasing specificity. Notably, our previous study [20] showed that 23 $\mu \mathrm{g} / \mathrm{mL}$ was a reasonable point for $1,5-\mathrm{AG}$ to screen for diabetes. In this study, the sensitivity and specificity were $81.5 \%$ and $67.7 \%$, respectively, at the point of $23.55 \mu \mathrm{g} / \mathrm{mL}$.

Table 2

Cut-points of 1,5-AG in detecting diabetic-specific retinopathy defined by sensitivity and specificity

\begin{tabular}{|lllllll|}
\hline & Sensitivity & Specificity & PPV & NPV & Accuracy & Youden \\
\hline $1,5-\mathrm{AG} \leq 12.85 \mu \mathrm{g} / \mathrm{mL}$ & $72.2 \%$ & $91.4 \%$ & $11.4 \%$ & $99.5 \%$ & $90.9 \%$ & 0.636 \\
\hline $1,5-\mathrm{AG} \leq 13.05 \mu \mathrm{g} / \mathrm{mL}$ & $74.1 \%$ & $91.2 \%$ & $11.4 \%$ & $99.6 \%$ & $90.9 \%$ & 0.653 \\
\hline $1,5-\mathrm{AG} \leq 14.65 \mu \mathrm{g} / \mathrm{mL}$ & $75.9 \%$ & $89.2 \%$ & $9.7 \%$ & $99.6 \%$ & $89.0 \%$ & 0.651 \\
\hline $1,5-\mathrm{AG} \leq 17.15 \mu \mathrm{g} / \mathrm{mL}$ & $77.8 \%$ & $85 \%$ & $7.4 \%$ & $99.6 \%$ & $89.0 \%$ & 0.628 \\
\hline $1,5-\mathrm{AG} \leq 19.25 \mu \mathrm{g} / \mathrm{mL}$ & $79.6 \%$ & $80.6 \%$ & $5.9 \%$ & $99.6 \%$ & $80.9 \%$ & 0.602 \\
\hline $1,5-\mathrm{AG} \leq 23.55 \mu \mathrm{g} / \mathrm{mL}$ & $81.5 \%$ & $67.7 \%$ & $3.7 \%$ & $99.6 \%$ & $68.0 \%$ & 0.492 \\
\hline PPV, positive predictive value; NPV, negative predictive value & & & \\
\hline
\end{tabular}

Multivariate logistic regression was constructed to investigate the association between 1,5-AG categories and DR. An 1,5-AG > $23.55 \mu \mathrm{g} / \mathrm{mL}$ was set as the reference group. Table 3 shows that participants with $1,5-A G \leq 13.05 \mu \mathrm{g} / \mathrm{mL}$ had about 6 times higher prevalence of any DR (OR 5.80, Cl 4.03-8.35, p<0.01) and about 25 times higher prevalence of diabetic-specific retinopathy (OR 25.16, Cl 12.08-52.39, $\mathrm{p}<$ 0.01 ) compared with $1,5-A G>23.55 \mu \mathrm{g} / \mathrm{mL}$. 
Table 3

Relationship between 1,5-AG categories and DR prevalence

\begin{tabular}{|lll|}
\hline 1,5-AG categories & Odds Ratio (95\%Cl) & \\
\hline & ETDRS $\geq 21$ & ETDRS $\geq 31$ \\
\hline$\leq 13.05 \mu \mathrm{g} / \mathrm{mL}$ & $* \star 5.80(4.03-8.35)$ & $* \star 25.16(12.08-52.39)$ \\
\hline $13.05-23.55 \mu \mathrm{g} / \mathrm{mL}$ & $1.38(0.94-2.04)$ & $1.01(0.31-3.29)$ \\
\hline$>23.55 \mu \mathrm{g} / \mathrm{mL}$ & 1.00 (Reference) & 1.00 (Reference) \\
\hline $\mathrm{Cl}, \mathrm{confidence}$ interval & & \\
\hline $\begin{array}{l}1,5-\mathrm{AG}>23.55 \mathrm{ug} / \mathrm{mL} \text { as the reference group. Data were adjusted for age, gender, BMI, hypertension, } \\
\text { Triglyceride, total cholesterol, HDL and LDL. }\end{array}$ \\
\hline “**” indicated for $\mathrm{p}<0.01$ & & \\
\hline
\end{tabular}

Table 4

Ability of 1,5-AG combined with FPG or HbA1c to diagnose diabetes in population without hypoglycemic drugs

\begin{tabular}{|c|c|c|c|c|c|}
\hline & Sensitivity & Specificity & PPV & NPV & Accuracy \\
\hline $1,5-\mathrm{AG} \leq 13.05 \mu \mathrm{g} / \mathrm{mL}$ & $54.2 \%$ & $93.5 \%$ & $5.7 \%$ & $99.7 \%$ & $93.6 \%$ \\
\hline $\mathrm{FPG} \geq 7.0 \mathrm{mmol} / \mathrm{L}$ & $41.7 \%$ & $93.5 \%$ & $4.5 \%$ & $99.6 \%$ & $83.1 \%$ \\
\hline $\mathrm{HbA} 1 \mathrm{c} \geq 6.5 \%$ & $45.8 \%$ & $87.1 \%$ & $3.4 \%$ & $99.6 \%$ & $86.8 \%$ \\
\hline 1,5-AG and $F P G^{*}$ & $41.7 \%$ & $96.7 \%$ & $8.4 \%$ & $99.6 \%$ & $96.4 \%$ \\
\hline 1,5-AG and $\mathrm{HbA} 1 \mathrm{c} \#$ & $41.7 \%$ & $96.6 \%$ & $8.0 \%$ & $99.6 \%$ & $96.2 \%$ \\
\hline \multicolumn{6}{|c|}{ *1,5-AG and FPG: individuals both met the criteria $1,5-\mathrm{AG} \leq 13.05 \mu \mathrm{g} / \mathrm{mL}$ and $\mathrm{FPG} \geq 7.0 \mathrm{mmol} /$} \\
\hline \multicolumn{6}{|c|}{$\# 1,5-\mathrm{AG}$ and $\mathrm{HbA} 1 \mathrm{c}$ : individuals both met the criteria $1,5-\mathrm{AG} \leq 13.05 \mu \mathrm{g} / \mathrm{mL}$ and $\mathrm{HbA} 1 \mathrm{c} \geq 6.5 \%$} \\
\hline
\end{tabular}

We then examined the cut-off point after excluding 202 participants who had antidiabetic medication, including 33 with ETDRS $\geq 31$. The AUC under the ROC curve (Supplementary Fig. 1) was 0.751 (0.6230.879). At the cut-off point of $13.05 \mu \mathrm{g} / \mathrm{mL}$, the sensitivity was $54.2 \%$ and the specificity was $93.5 \%$. Meanwhile, the sensitivities and specificities were $41.7 \%$ and $93.5 \% 45.8 \%$ and $87.1 \%$ for $\mathrm{HbA} 1 \mathrm{c}$ at $6.5 \%$. The combination of 1,5-AG with FPG or HbA1c could increase the specificities to $96.7 \%$ and $96.6 \%$, and also increase positive predictive values (PPV) to $8.4 \%$ and $8.0 \%$.

\section{Discussion}


There has been increasing attention to 1,5-AG as a new kind of glycemic index. Several studies have explored the possibility of using 1,5-AG to diagnose diabetes for its relatively convenient and low-cost measuring procedure. Yamanouchi et al. [4] found the best cut-off point was $14.0 \mu \mathrm{g} / \mathrm{mL}$ and Goto's group [5] recommended $14.2 \mu \mathrm{g} / \mathrm{mL}$. Our previous study explored the reference intervals of $1,5-\mathrm{AG}$ and found that the inferior threshold of the healthy population was around $14-16 \mathrm{ug} / \mathrm{mL}$ [13]. One study from Shanghai [21] pointed out that the best point of 1,5-AG for screening diabetes was $15.9 \mathrm{ug} / \mathrm{mL}$, and the sensitivity and specificity were $69.2 \%$ and $72.3 \%$, respectively.

As we know, this research explored the cut-off points of 1,5-AG for diagnosing diabetes in China based on diabetic-specific retinopathy for the first time. We found $13.05 \mu \mathrm{g} / \mathrm{mL}$ was the most effective point for diagnosis. This was in accordance with former conclusions $[4,5,13,21]$. The sensitivities were partly sacrificed to ensure higher specificities to avoid overdiagnosis of diabetes, causing an extra burden on the healthcare system. This was why our recommended point was a little lower than some previous results. We also analyzed other points with a relatively high Youden index and found that elevation of the cut-off point may raise the sensitivity a little, but reduce the specificity and PPV greatly. Thus, $13.05 \mu \mathrm{g} / \mathrm{mL}$ was a reasonable cut-off point.

We further examined this point after excluding those participants using hypoglycemic drugs and found 1,5-AG had similar ability with FPG in discriminating diabetic-specific retinopathy with a specificity of 93.5\%. Moreover, 1,5-AG had even higher sensitivity and PPV than FPG in this group. Epidemiology [22] showed that $50 \%$ of Chinese patients with diabetes only had elevated postprandial blood glucose, which meant using FPG only would miss large quantities of diabetes. A previous study found that 1,5-AG had a good correlation with blood glucose, especially postprandial glucose, and this relationship existed even in impaired glucose tolerance and pre-diabetes groups [23-25]. In our study, we did not practice OGTT among patients who had already been diagnosed with diabetes or had an $\mathrm{FPG} \geq 7.0 \mathrm{mmol} / \mathrm{L}$ for the sake of safety. However, we still found a significant negative correlation between 1,5-AG and $2 \mathrm{hPG}$ in the diabetic-specific retinopathy group, with a correlation coefficient of -0.753 . Therefore, we supposed that 1,5-AG provided an advantage in diagnosing diabetes with elevated postprandial glucose.

According to the guideline [26], two abnormal test results from the same sample or in two separate samples are required for diagnosis in those who do not have typical clinical symptoms. Many early-stage patients often have an absence of classic symptoms in the clinic, which means a repeated FPG test on another day or an OGTT test is required. And this may lead to a waste of money and time. Since 1,5-AG was effective with postprandial glucose, the combination of 1,5-AG and FPG could substitute for OGTT in some way. We found that 1,5-AG in combination with FPG or HbA1c could both improve the specificities over $95 \%$, and also increase the PPVs, thus preventing overdiagnosis and overtreatment of diabetes. Although a previous study [27] found that glucose load could slightly elevate extracellular 1,5-AG levels, it had a negligible impact on serum 1,5-AG levels due to the existence of a large 1,5-AG pool in the human body [1]. Thus, we considered the level of 1,5-AG to be relatively stable in one day and independent of fasting. Random blood samples were qualified enough for diagnosis. We suggested choosing two to three indicators based on the individual conditions of patients to simplify the diagnostic process. 
Previous studies tended to choose moderate DR as the gold standard when exploring the threshold of one glycemic indictor. This is because in addition to hyperglycemia, hypertension, and hyperlipidemia are also risk factors for DR $[28,29]$. In this research, among 196 patients with any kind of DR (ETDRS $\geq 21$ ), only 88 had diabetes (including newly diagnosed diabetes and self-reported diabetes). Among the remaining 108 participants, 80 had hypertension or hyperlipidemia. The area under the ROC curve based on ETDRS $\geq 21$ was only 0.66 , which meant 1,5 -AG had a poor ability to discriminate between non-specific DR. Therefore, we chose ETDRS $\geq 31$, identified as diabetic-specific retinopathy, as the gold standard, referring to some previous studies [10, 30,31]. According to Wisconsin research [19], the definition of level 31 was "Microaneurysms and one or more of the following: venous loops $31 \mu$ or greater; questionable soft exudate, intraretinal microvascular abnormalities or venous beading, and retinal hemorrhages." However, there were still 11 participants without diabetes in the group of ETDRS $\geq 31$ (Supplementary Fig. 3). Interestingly, 7 of these 11 individuals had 1,5-AG levels under $13.05 \mu \mathrm{g} / \mathrm{mL}$. We could not explain whether these people were non-diabetic individuals with shifting 1,5-AG levels or true diabetic patients missed by the OGTT test unless further follow-up investigations were conducted. If raising the level of ETDRS level up to 43 (moderate NPDR), only 20 individuals remained in this group, and only 1 of them was without diabetes. This is in accordance with the comparatively low prevalence of DR in China [10]. The area under the ROC curve based on level 43 could be up to 0.952 (Supplementary Fig. 2). The most effective point to diagnose was still $13.05 \mu \mathrm{g} / \mathrm{mL}$, with sensitivity and specificity up to $95 \%$ and $90.7 \%$, respectively. DR became more specific with the rising ETDRS level, becoming more representative of diabetes. However, excessive strict definition for diabetic-specific retinopathy would cause a large amount of missing data on diabetes. Taken together, we still chose retinopathy with ETDRS $\geq 31$ to indicate the existence of diabetes.

Our research had several limitations. First, we considered whether to exclude those participants using hypoglycemic drugs, as many previous studies did. In this study, most diabetic-specific retinopathy individuals were on hypoglycemic treatment. Excluding these participants would lead to huge numbers of missing data and cause bias. However, inclusion of these people could influence the level of 1,5-AG since it was sensitive to glucose fluctuations, resulting in a predicted threshold higher than the true level. This contradiction has been discussed at length in many other studies [10,11,32,33]. Our decision was to establish the threshold in the total population and then examined it in the non-treated group. We found that the optimal diagnostic point remained effective after excluding individuals under treatment. Second, this was a cross-sectional study, and we could not tell the relationship between 1,5-AG and the incidence of DR. Third, we found that 1,5-AG was influenced by gender, uric acid, and renal function in our previous study [13], but we did not adjust these factors in this study. We expect to make improvements in future research.

\section{Conclusion}

In summary, we explored the relationship between serum 1,5-AG and the prevalence of diabetic-specific retinopathy. Our data proved that a 1,5-AG of $13.05 \mu \mathrm{g} / \mathrm{mL}$ was reasonable to diagnose diabetes with excellent specificity. The combination of 1,5-AG with FPG or HbA1c was a good method to diagnose 
diabetes without clinical symptoms, and it is worth being promoted in communities and outpatient departments.

\section{Abbreviations}

1,5-AG, 1,5-anhydroglucitol; ETDRS, Early Treatment Diabetic Retinopathy Study; FPG, fasting plasma glucose; 2hPG, 2-hour postprandial glucose; HbA1c, glycated haemoglobin

\section{Declarations}

\section{Ethics approval and consent to participate}

The protocol was registered with approval number:2016ZDSYLL092-P01

\section{Consent for publication}

Not applicable

\section{Availability of data and materials}

The datasets generated and/or analyzed during the current study are not publicly available but are available from the corresponding author on reasonable request.

\section{Acknowledgements}

We owe our sincere thanks to the local research teams and colleagues for assistance in participant recruitment. We are grateful to many residents of Jiangsu and Xinjiang Province who participated in this study.

\section{Fundings}

This work was supported by the National Key R\&D Program of China (grant No. 2016YFC1305700), the National Key Scientific Instrument and Equipment Development Project of China (grant No. 51627808), The funders had no role in the design of the study; collection, analysis, and interpretation of data; or in writing or submitting this manuscript.

\section{Competing interests}

The authors declare that they have no competing interests

\section{Contributions}


Wang YAO and Zilin SUN, the corresponding authors of this manuscript, organized the research and advised on the writing of article. Cheng CHEN analyzed data and wrote the manuscript. Shanhu QIU, Ziwei DU, Haijian GUO, Bei WANG made the equal contributions to this article with some assistance in revising manuscript, and statistics. And the other co-authors helped in collecting the samples and the laboratory examination. This manuscript has been read by each co-author and all authors are in agreement with the content of the manuscript.

\section{References}

1. Yamanouchi T, Tachibana Y, Akanuma H, Minoda S, Shinohara T, Moromizato H, et al. Origin and disposal of 1,5-anhydroglucitol, a major polyol in the human body. Am J Physiol. 1992 Aug;263(2 Pt 1):E268-73. doi:10.1152/ajpendo.1992.263.2.E268.

2. Dungan KM, Buse JB, Largay J, Kelly MM, Button EA, Kato S, et al. 1,5-anhydroglucitol and postprandial hyperglycemia as measured by continuous glucose monitoring system in moderately controlled patients with diabetes. Diabetes Care. 2006 Jun;29(6):1214-9. doi:10.2337/dc06-1910.

3. Akanuma Y, Morita M, Fukuzawa N, Yamanouchi T, Akanuma H. Urinary excretion of 1,5-anhydro-Dglucitol accompanying glucose excretion in diabetic patients. Diabetologia. 1988 Nov;31(11):831-5. doi: 10.1007/BF00277486.

4. Yamanouchi T, Akanuma Y, Toyota T, Kuzuya T, Kawai T, Kawazu S, et al. Comparison of 1,5anhydroglucitol, $\mathrm{HbA1C}$, and fructosamine for detection of diabetes mellitus. Diabetes. 1991 Jan;40(1):52-7. doi:10.2337/diab.40.1.52.

5. Goto M, Yamamoto-Honda R, Shimbo T, Goto A, Terauchi Y, Kanazawa Y, et al. Correlation between baseline serum 1,5-anhydroglucitol levels and 2-hour post-challenge glucose levels during oral glucose tolerance tests. Endocr J. 2011;58(1):13-7. doi:10.1507/endocrj.k10e-224.

6. Shirasaya K, Miyakawa M, Yoshida K, Takahashi E, Shimada N, Kondo T. Economic evaluation of alternative indicators for screening for diabetes mellitus. Prev Med. 1999 Aug;29(2):79-86. doi:10.1006/pmed.1999.0506.

7. Ying L, He X, Ma X, Shen Y, Su H, Peng J, et al. Serum 1,5-anhydroglucitol when used with fasting plasma glucose improves the efficiency of diabetes screening in a Chinese population. Sci Rep. 2017 Sep 20;7(1):11968. doi: 10.1038/s41598-017-12210-z.

8. McCance DR, Hanson RL, Charles MA, Jacobsson LT, Pettitt DJ, Bennett PH, et al. Comparison of tests for glycated haemoglobin and fasting and two hour plasma glucose concentrations as diagnostic methods for diabetes. BMJ. 1994 May 21;308(6940):1323-8. doi: 10.1136/bmj.308.6940.1323.

9. McCance DR, Hanson RL, Charles MA, Jacobsson LT, Pettitt DJ, Bennett PH, et al. Which test for diagnosing diabetes? Diabetes Care. 1995 Jul;18(7):1042-4. doi: 10.2337/diacare.18.7.1042.

10. Sabanayagam C, Khoo EY, Lye WK, Ikram MK, Lamoureux EL, Cheng CY, et al. Diagnosis of diabetes mellitus using $\mathrm{HbA} 1 \mathrm{c}$ in Asians: relationship between $\mathrm{HbA} 1 \mathrm{c}$ and retinopathy in a multiethnic Asian population. J Clin Endocrinol Metab. 2015 Feb;100(2):689-96. doi:10.1210/jc.2014-2498. 
11. Colagiuri S, Lee CM, Wong TY, Balkau B, Shaw JE, Borch-Johnsen K, DETECT-2 Collaboration Writing Group. Glycemic thresholds for diabetes-specific retinopathy: implications for diagnostic criteria for diabetes. Diabetes Care. 2011 Jan;34(1):145-50. doi:10.2337/dc10-1206.

12. Wong TY, Liew G, Tapp RJ, Schmidt MI, Wang JJ, Mitchell P, et al. Relation between fasting glucose and retinopathy for diagnosis of diabetes: three population-based cross-sectional studies. Lancet. 2008 Mar 1;371(9614):736 - 43. doi: 10.1016/S0140-6736(08)60343-8.

13. Chen C, Wang X, Tan Y, Yang J, Yuan Y, Chen J, et al. Reference intervals for serum 1,5anhydroglucitol of a population with normal glucose tolerance in Jiangsu Province. J Diabetes. 2020 Jun;12(6):447-54. doi:10.1111/1753-0407.13016.

14. Tanaka S, Nakamori K, Akanuma H, Yabuuchi M. High performance liquid chromatographic determination of 1,5-anhydroglucitol in human plasma for diagnosis of diabetes mellitus. Biomed Chromatogr. 1992 Mar-Apr;6(2):63-6. doi:10.1002/bmc.1130060204.

15. World Health Organization. Definition, Diagnosis and Classification of Diabetes Mellitus and Its Complications: Report of a WHO Consultation. (accessed March 12, 2013).

16. Diabetic Retinopathy Study Research Group. Report VII: a modification of the Airlie House classification of diabetic retinopathy. Invest Ophthalmol Vis Sci. 1981;21:210-26.

17. Klein R, Klein BE, Magli YL, Brothers RJ, Meuer SM, Moss SE, et al. An alternative method of grading diabetic retinopathy. Ophthalmology. 1986 Sep;93(9):1183-7. doi:10.1016/s0161-6420(86)33606-6.

18. Klein R, Knudtson MD, Lee KE, Gangnon R, Klein BE. The Wisconsin Epidemiologic Study of Diabetic Retinopathy XXIII: the twenty-five-year incidence of macular edema in persons with type 1 diabetes. Ophthalmology. 2009 Mar;116(3):497-503. doi:10.1016/j.ophtha.2008.10.016.

19. Klein R, Klein BE, Moss SE, Cruickshanks KJ. The Wisconsin Epidemiologic Study of diabetic retinopathy. XIV. Ten-year incidence and progression of diabetic retinopathy. Arch Ophthalmol. 1994 Sep;112(9):1217-28. doi:10.1001/archopht.1994.01090210105023.

20. Qian J, Chen C, Wang X, Tan Y, Yang J, Yuan Y, et al. HbA1c combined with glycated albumin or 1,5anhydroglucitol improves the efficiency of diabetes screening in a Chinese population. Diabet Med. 2021 Sep;2:e14685. doi:10.1111/dme.14685.

21. Ying L, He X, Ma X, Shen Y, Su H, Peng J, et al. Serum 1,5-anhydroglucitol when used with fasting plasma glucose improves the efficiency of diabetes screening in a Chinese population. Sci Rep. 2017 Sep 20;7(1):11968. doi: 10.1038/s41598-017-12210-z.

22. Chinese Diabetes Society. Guidelines for prevention and treatment of type 2 diabetes in China(2013 version). Chin J Diabetes. 2014;22:appendix.

23. Christensen BL, Williams M. Assessing postprandial glucose using 1,5-anhydroglucitol: An integrative literature review. J Am Acad Nurse Pract. 2009 Oct;21(10):542-8. doi:10.1111/j.17457599.2009.00443.x.

24. Yamanouchi T, Inoue T, Ogata E, Kashiwabara A, Ogata N, Sekino N, et al. Post-load glucose measurements in oral glucose tolerance tests correlate well with 1,5-anhydroglucitol, an indicator of 
overall glycaemic state, in subjects with impaired glucose tolerance. Clin Sci (Lond). 2001 Sep;101(3):227-33.

25. Won JC, Park CY, Park HS, Kim JH, Choi ES, Rhee EJ, et al. 1,5-Anhydroglucitol reflects postprandial hyperglycemia and a decreased insulinogenic index, even in subjects with prediabetes and wellcontrolled type 2 diabetes. Diabetes Res Clin Pract. 2009 Apr;84(1):51-7. doi:10.1016/j.diabres.2009.01.002.

26. American Diabetes Association. 2. Classification and Diagnosis of Diabetes: Standards of Medical Care in Diabetes-2020. Diabetes Care. 2020;43(Suppl 1):14-31.

27. Ying L, Ma X, Yin J, Wang Y, He X, Peng J, et al. The metabolism and transport of 1,5-anhydroglucitol in cells. Acta Diabetol. 2018 Mar;55(3):279-286. doi:10.1007/s00592-017-1093-8.

28. Wong TY, Mitchell P. The eye in hypertension. Lancet. 2007 Feb 3;369(9559):425 - 35. doi: 10.1016/S0140-6736(07)60198-6.

29. Agroiya P, Philip R, Saran S, Gutch M, Tyagi R, Gupta KK. Association of serum lipids with diabetic retinopathy in type 2 diabetes. Indian J Endocrinol Metab. 2013 Oct;17(Suppl 1):S335-7. doi: 10.4103/2230-8210.119637.

30. Sabanayagam C, Liew G, Tai ES, Shankar A, Lim SC, Subramaniam T, et al. Relationship between glycated haemoglobin and microvascular complications: is there a natural cut-off point for the diagnosis of diabetes? Diabetologia. 2009 Jul;52(7):1279-89. doi: 10.1007/s00125-009-1360-5.

31. Cho NH, Kim TH, Woo SJ, Park KH, Lim S, Cho YM, et al. Optimal HbA1c cutoff for detecting diabetic retinopathy. Acta Diabetol. 2013 Dec;50(6):837-42. doi:10.1007/s00592-013-0452-3.

32. Xin Z, Yuan MX, Li HX, Hua L, Feng JP, Shi J, et al. Evaluation for fasting and 2-hour glucose and $\mathrm{HbA} 1 \mathrm{c}$ for diagnosing diabetes based on prevalence of retinopathy in a Chinese population. PLoS ONE. 2012;7(7):e40610. doi:10.1371/journal.pone.0040610.

33. Cheng YJ, Gregg EW, Geiss LS, Imperatore G, Williams DE, Zhang X, et al. Association of A1C and fasting plasma glucose levels with diabetic retinopathy prevalence in the U.S. population: Implications for diabetes diagnostic thresholds. Diabetes Care. 2009 Nov;32(11):2027-32. doi:10.2337/dc09-0440.

\section{Figures}




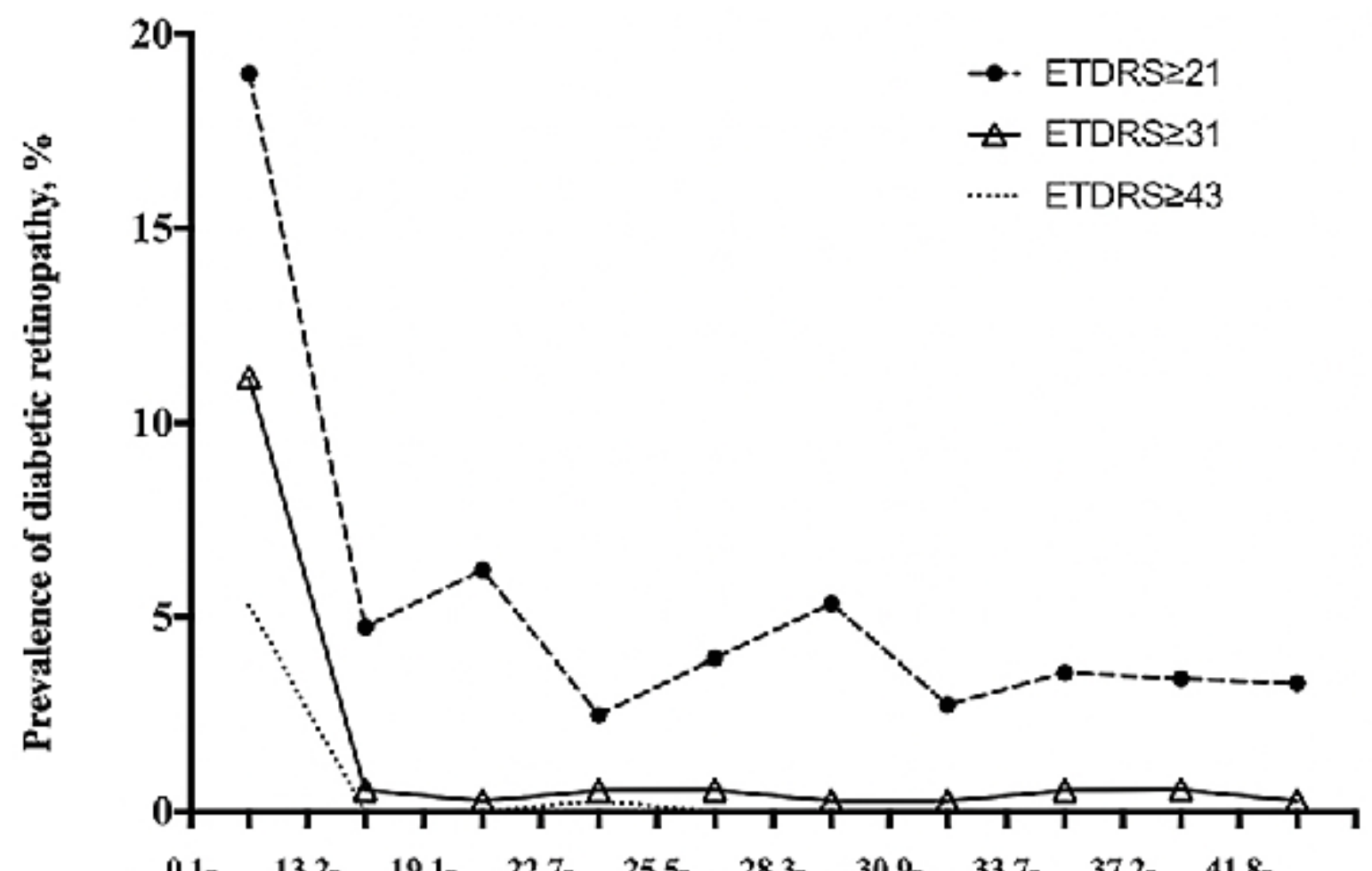

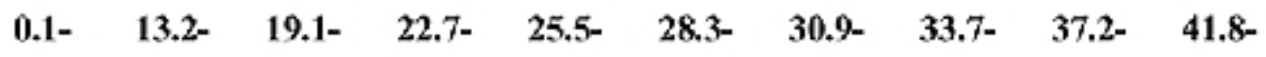

\section{1,5-anhydroglucitol categories, $\mu \mathrm{g} / \mathrm{mL}$}

Figure 1

Prevalence of different levels of diabetic retinopathy by deciles of 1,5-AG distribution
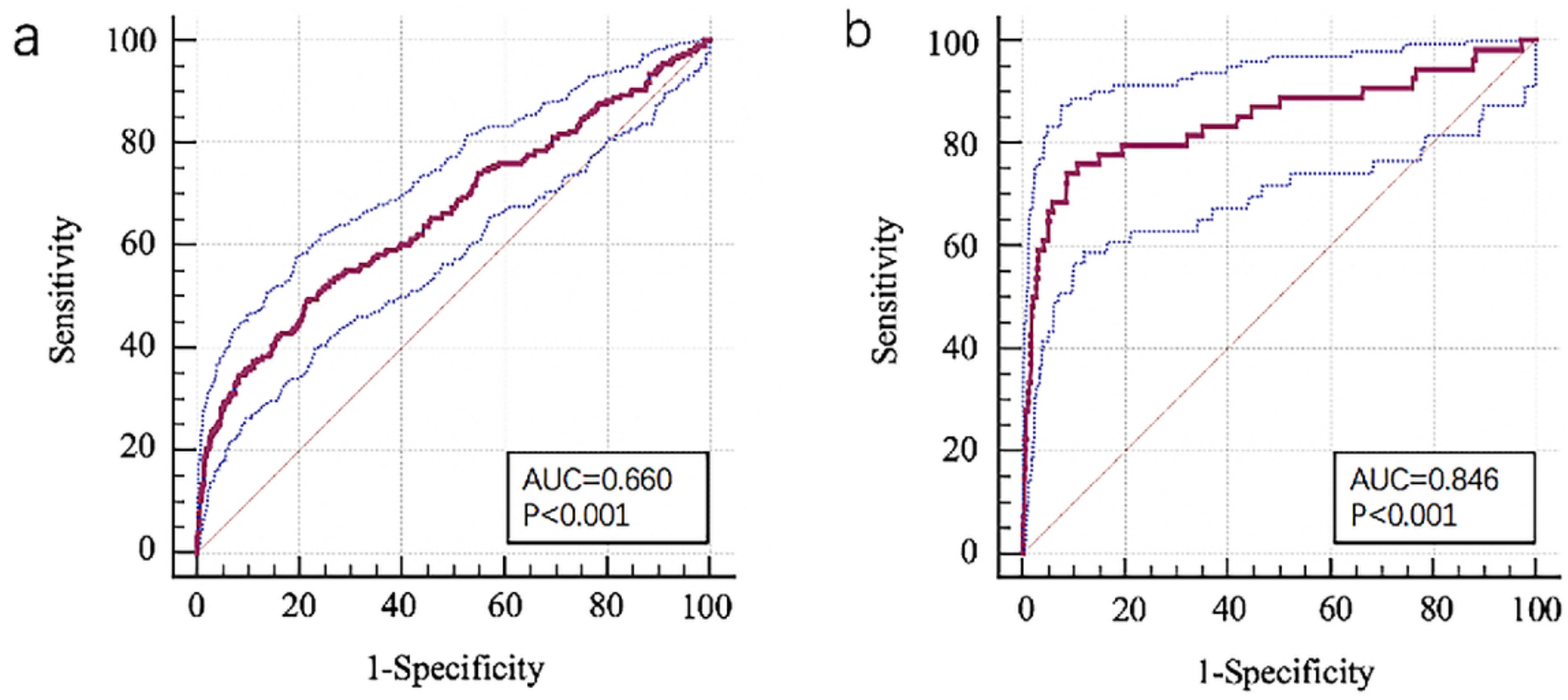

Figure 2 
Receiver operating characteristics (ROC) curves for 1,5-AG to predict the presence of different levels of diabetic retinopathy. (a) any DR (ETDRS $\geq 21)$;(b) diabetic-specific retinopathy (ETDRS $\geq 31$ )

\section{Supplementary Files}

This is a list of supplementary files associated with this preprint. Click to download.

- Supplementarymaterial.docx 